\title{
The Determinants of Credit Rationing in Tunisia: A Survey among Credit Managers
}

\author{
Manel Mazioud Chaabouni ${ }^{1} \&$ Nadia Selmi ${ }^{2}$ \\ ${ }^{1}$ l'institut supérieur de commerce et comptabilité de Bizerte, Tunisia \\ ${ }^{2}$ Faculté des sciences économiques et de gestion de Tunis, Tunisia \\ Correspondance: Nadia Selmi, Faculté des sciences économiques et de gestion de Tunis, Tunisia. Tel: \\ 216-2477-6655. E-mail: selminadia1@ gmail.com
}

Received: February 13, 2016

Accepted: March 21, 2016

Online Published: April 25, 2016

doi:10.5539/ijef.v8n5p151

URL: http://dx.doi.org/10.5539/ijef.v8n5p151

\begin{abstract}
This paper aims at explaining the financing structure of the Tunisian companies by the information asymmetry phenomenon as well as at checking whether the low share of loans in the financing of the Tunisian companies is reflected in a credit rationing. We have focused on the informational factor between banks and corporates since the contract between lenders and borrowers may include some limitations even if the legal rules do exist and are properly applied. Our analysis deals with the credit operations. We have restricted our study to the case of small and medium enterprises seeing their importance in our industrial network. We have analyzed the behavior of credit managers dealing with loan applications based on a survey addressed to the credit managers of small and medium enterprises. Our results suggest that Tunisian credit managers be risk averse-which results in a credit rationing. The estimates display that the reliability of accounting documents, the risk of adverse selection and the inefficient recovery procedures are the determinant of this rationing.
\end{abstract}

Keywords: credit market, credit rationing, information asymmetry, financing structure, small \& medium enterprises

\section{Introduction}

The link between the company size, the funding level in the marketplace and the level of bank indebtedness has been extensively treated by the economic literature. Unable to fulfill the conditions of access to the financial market, a small or a medium company should normally apply to a financial intermediary to finance its investments. Once it has built up a reputation in the credit market, raising funds from the financial market becomes possible by issuing debt securities (Diamond, 1991).

In the credit market, the relationship between banks and small and medium companies is quite complex. On the one hand, most entrepreneurs perceive bankers to be very demanding criticizing them for not taking enough risks in their engagements, which can seriously hinder the funding of their activities even for the most creditworthy ones. On the other hand, bankers claim insufficient initial own funds of firms, the unreliability of the accounting documents submitted, the lack of collateral warranties and the absence of an effective corporate governance system. They also emphasize two major problems which may explain the banks credit rationing: the risk of adverse selection and the moral hazard carried by asymmetric information between lenders and borrowers before and after signing the contract.

Generally, rationing means the refusal of the banking sector to lend these corporates at rate conditions and quantities requested (The interest rate reflects the charges incurred by the Bank as refinancing costs in the money market, the management fees, the bank margin and also the risk premium required to compensate for losses in the case of a default of payment by the borrower). This occurs once the banks are no longer able to distinguish between bad borrowers (insolvent) and good borrowers (solvent). In this context, information asymmetries can transform the modes of financing companies and in general, the funding structure of an economy. The empirical literature has shown that the firms' access to bank financing depends mainly on their information transparency (Peterson \& Rajan, 2002). Indeed, due to this asymmetric information, the banks will be unable to evaluate the probability of default of the project for which they are requested, especially in the case of small and medium enterprises that are hard-assessing organizations for their complex financial structure and their family-type 
concentrated control system. The leaders of such structures are not always willing to transmit the accounting and financial data of their activities essentially for fiscal reasons. In such family structures, the managers are generally not very competent. They use very few technical signaling and risk forecasts. Even private agencies for the collection and the dissemination of information are rather skeptical to invest in such opaque structures (Binks, Ennew, \& Reed, 1991).

After a review of the economic literature, we will present the different models which have dealt with this problematic as Jaffee and Modigliani (1969), Jaffee and Russel (1976), and Stiglitz and Weiss (1981) models. We will explain the corporate finance structure through an approach of incomplete contracts on the one hand and the nature of bankruptcy laws that protect both debtors and creditors on the other hand. We will then analyze the behavior of those credit managers and highlight the determinants of credit rationing by using a semi-directive survey.

\section{The Credit Rationing: Theoretical Arguments}

In a certain universe (information is free), the bank can clearly evaluate all the actions of the borrowers that could subsequently affect the probability of repayment of the loan, borrowers always respect their commitments and the probability of failure is almost zero (no risk of bankruptcy). But in the presence of an information asymmetry assumption, the bank is no more able to directly control the actions of borrowers. Arise then the phenomena of adverse selection and moral hazard. This information asymmetry means that the two transaction actors, do not have the same information, which may generate the appearance of an opportunistic behavior by borrowers. In most cases, the borrower knows very well the expected return of his project, whereas the lender has only the part of the information transmitted by the entrepreneur. This opacity often leads the lender to overestimate or underestimate the company's failure probabilities and hence to the risk of adverse selection.

After signing the contract, the borrower can risk too much by not following the devices of the loan agreement. The information banker has on what the agent is doing is incomplete, arise hence the risk of moral hazard (the company will use the money lent for other purposes than those specified in the contract, increasing then its probability of default).

This uncertainty often urges banks to implement specified terms of the loan agreement such as the requirement of restrictive clauses in order to encourage the borrower to meet its commitments. But in some situations, the bank is obliged to limit the volume of loans granted rather than raise the interest rate that incorporates the risk premium since only the riskiest companies accept to borrow in such conditions. In this case, the equilibrium on the credit market is no longer reached by the prices but by quantities (Stiglitz \& Weiss, 1981). Unfortunately, such behavior would compromise the chances of solvent companies to access to bank loans to finance profitable projects. The presence of asymmetric information makes the task of discerning between bad and good borrowers quite difficult, hence the credit rationing. It is no more possible to balance the credit market by influencing the price of credit: the interest rate.

Referring to the economic literature, four situations- each- reflecting a specific type of rationing have been established:

- When the bank grants a credit for an amount less than requested. To get a larger amount, the borrower has to incur a higher rate. In this case, the adjustment between supply and demand is reached through the price (Keeton, 1979).

- When the bank refuses to finance some borrowers with the same characteristics as those who have already obtained a loan and are willing to incur high interest rates and present fairly significant collateral. In this case, the adjustment is made by the quantities. We talk about "pure rationing." (Stiglitz \& Weiss, 1981).

- When the bank refuses the interest rate proposed by the borrower and then rejects the financing request. This behavior has been developed by Hodgman (1960) who built his analysis on the fact that expectations of bankers differ from those of firms.

- When the bank refuses to commit to a credit relationship with the borrower judged too risky, deviating him from the market even if he has sufficient liquidity. In this case, we talk about "red-lining". Such type of behavior is often observed in developing countries (Stiglitz \& Weiss, 1981; Joseph, 2000).

\section{The Purpose and Aim of the Survey}

The purpose of this survey is to provide a clearer idea about the quality of the relationship between the company and the Tunisian bank. Several empirical studies have been conducted to study the hypothesis of rationing of credit to businesses. We essentially mention the opinion surveys and the use of proxy variables. Achieving a 
survey among small \& medium enterprises (SME) client's managers involves a new empirical research track. We chose to make a semi-structured interview with credit managers. The first objective sought is to see whether we can actually affirm the existence of credit rationing in Tunisia. We will evaluate, therefore, the extent of the credit rationing by investigating the attitude of the banks in front of the demands of business financing. Then, we will identify the determinants of this behavior on the basis of four key variables:

- The nature of the credit supply capacity;

- The quality of the application:

- $\quad$ Ex ante asymmetric information and anti-selection risk;

- $\quad$ Ex post information asymmetry and moral hazard.

- The lack of warranties;

- The nature of the recovery procedures, which is one of the important aspects of the debt contract signed.

\subsection{The Target Population}

The size of the representative sample is of 120 loan officers, 100 in the banking agencies and 20 at headquarters selected by a list provided by the Central Bank of Tunisia (BCT). Their characteristics are presented in Appendix 1.

Table 1. Distribution of the 120 credit managers interviewed

\begin{tabular}{lcc}
\hline & banking agencies & banking headquarters(Located at the center of Tunis) \\
\hline Northern Region & 50 & 20 \\
Central Region & 30 & - \\
Southern Region & 20 & - \\
Total & $\mathbf{1 0 0}$ & $\mathbf{2 0}$ \\
\hline
\end{tabular}

\subsection{The Presentation of the Survey}

The survey was conducted from $12^{\text {th }}$ January to $30^{\text {th }}$ April 2015. The questionnaire was accompanied by a cover letter that was intended to explain the objectives of the investigation and to invite the credit manager to express their real opinions.

The investigation is made up-firstly-by closed questions and then by open-ended questions that give the bankers the opportunity to sometimes answers freely. It consists of 50 questions that deal with all the axes developed in theory which we have grouped into four parts:

The first part relates to the nature of the banks' credit supply capacity regardless of the nature and the request.

The second part will treat, in a first stage, the ex-ante asymmetric information between the bank and the company as the nature of the information environment, the reliability of accounting documents and subsequently the presence of the adverse selection risk. We will identify according to which criteria, the credit manager selects good projects from the bad.

In a second step, the survey refers to the presence of the ex post problem of asymmetry of information (the existence of moral hazard) which results in the risk of opportunism by borrowers and the nature of control of funds granted (monitoring).

The third part will focus on the nature of the guarantees required by the banker.

In the fourth part, we will identify how the malfunctioning recovery procedure, in case of bankruptcy of enterprises, encourages banks not to commit.

In a second step, the survey refers to the presence of the ex post asymmetry information problem (the existence of moral hazard) resulting in the borrowers risk of opportunism and the nature of control of the funds granted (monitoring). In the third part, we will focus on the nature of the guarantees required by the banker. The fourth part is aimed at demonstrating how the dysfunctional recovery procedure, in case of bankruptcy of enterprises, encourages banks not to engage. In the last part we will identify the capacity of Tunisian banks to mitigate the adverse selection and moral hazard problems if they exist.

\subsection{The Method of Operating Data}

To exploit the data, we have transformed the responses of the credit managers in order to make them operational 
and usable by the data processing software (SPSS). Variables (labels) are coded as follows: if the answer is "often", the variable is set to 1 . If the answer is "sometimes" it is set to 2 . If the answer is "never", the variable takes the value 3. it is an ordinal variable. There are also questions of scales type as the questions (see Appendix 2): A1, A2, C9, G3, G8, H2, I1, I2, I3, J1 et J2. They are coded the same manner: 1, 2, 3.

\section{The Determinants of Credit Rationing: LOGIT Model}

We will highlight what the variables- that actually influence the credit rationing decision by the banker. We have then to summarize the information collected as components to include them subsequently in a logit model as explanatory variables of the "credit rationing" phenomenon in order to determine how these components determine the credit rationing in Tunisia.

\subsection{Construction of the Explanatory Variables through the Principal Component Analysis Method (PCA)}

The PCA is a geometrical descriptive method that allows us to better understand our variables. Representing the variables as points in a geometric space allows us to better view the different linear connections between them. It consists in standing out what the most correlated variables are and those which are not, through the construction of axes. Each axis includes the similar variables. These new variables are called "principal components" noted $\mathrm{Z}_{\mathrm{k}}$ representing the new variable corresponding to the axis.

$$
Z_{K}=\sum_{j}^{p} a_{K j} V_{c j}
$$

$\alpha_{k j}$ is the $\mathrm{j}^{\text {th }}$ coordinate of the directing vector $\mathrm{a}_{\mathbf{k}}$ of ${ }_{\Delta_{K}}$.

\subsubsection{The Credit Supply Capacity: PCA1( See Appendix 3)}

From the amount of information that deals with the nature of the bankers' credit supply capacity, we have built through the PCA method two representative axes of the first determinant:

- $\quad$ Axis1: $\mathrm{f}(\mathrm{b} 1, \mathrm{~b} 2)$ : respect of the prudential ratios (R.PRUD);

- Axis2: $\mathrm{f}(\mathrm{b} 3, \mathrm{~b} 4)$ : importance of doubtful debts(I.CRD).

The PCA1 shows that KMO slightly exceeds 0.5 and Bartlett's test shows that the representation is significant at the order of $5 \%$.

From the quality of the representation, we could assert that most of the variables are well presented. The application of principal component analysis allowed us to construct two axes that explain the nature of the bankers' credit supply capacity:

- Axis $1=\mathrm{f}(\mathrm{b} 1, \mathrm{~b} 2)$ entitled "respect of the prudential ratios (R.PRUD)" explains 33.8\% of the limitation of the credit supply capacity.

- Axis $2=\mathrm{f}(\mathrm{b} 3, \mathrm{~b} 4)$ entitled "importance of doubtful debts (I.DD)" explains $25.4 \%$ of the phenomenon studied.

In total, these components explain $59.22 \%$ of the total variance of the limitation of the credit supply capacity.

From the total variance explained, we note that the first component reflecting the effect of R.PRUD on credit supply capacity is the most significant (33.8\%). After building the components of credit supply capacity that will later be integrated to estimate the determinants of credit rationing, we will consider the nature of the request.

4.1.2 The Ex- Ante Asymmetric Information: PCA2 (See Appendix 4)

The collected data allowed us to build 3 axes:

- $\quad$ Axis 1: $\mathrm{f}(\mathrm{C} 3, \mathrm{C} 5)$ : the nature of the information environment (N.EINF);

- Axis 2: $\mathrm{f}(\mathrm{C} 4, \mathrm{C} 6, \mathrm{C} 7)$ : the reliability of the accounting documents (R.DOC);

- Axis3: (C8, C9): theanti-selection problem (ANTISEL).

Although the Bartlett test $(0,138)$ and the $\operatorname{KMO}(0,464)$ are rather weak, our main objective is to summarize the quantity of information that relates to the existence of the ex-ante asymmetry problem as components (axes) to explain later, our major problem being the credit rationing.

At this stage, we can say that only 5 variables are well presented $\left(b_{10}, b_{11}, b_{12}, b_{13}, c_{1}, c_{2}\right)$.

The application of principal component analysis has allowed us to build three axes representing the problem of ex-ante asymmetry information:

- Axis 1 entitled "Nature of information environment (N.EINF)" explains 19,88\% of the presence of the 
asymmetry information before the signature of the financing agreement.

- Axis 2 entitled "reliability of the accounting documents (R.DOC)" represents the problem of ex-ante asymmetry information to the order of $18.36 \%$.

- Axis 3 entitled "anti-selection problem (ANTISEL)" represents $15,39 \%$ of the studied problem.

In total, these components explain the total variance of the ex-ante information asymmetry at the order of $53.64 \%$. The matrix of the components shows that among the three axes constructed, the first axis (Z1) which reflects the nature of the information environment is the most significant.

\subsubsection{The Ex-Post Information Asymmetry}

From the information collected, we have tried to build a component that represents the moral hazard problem, but we have not been able to do it since the KMO index and Bartlett are far from significant. For this reason we have included in our logit model, the only variable that can highlight the opportunism risk borrowers "OPP.B" in an individual way.

\subsubsection{The Guarantees: PCA4 (see Appendix 6)}

- Axis1: $\mathrm{f}(\mathrm{E} 1, \mathrm{E} 2)$ : the lack of guarantees (GARANTI).

The PCA4 shows that the KMO is 0.5 and the Bartlett's test (0.89) shows that the representation is significant at the order of $10 \%$. The quality of the representation shows that the two variables selected highlighting the collateral requirement issue are well presented $(0,578)$.

Only one axe representing the guarantee requirement issue was possible to build:

Axis $=\mathrm{f}(\mathrm{E} 1, \mathrm{E} 2)$. This component explains the total variance guarantees of around $57.79 \%$.

\subsubsection{Dysfunction of Recovery Procedures: PCA 5 (See Appendix 7)}

4 axes representing the dysfunction of the recovery procedures in case of bankruptcy of the company had been built

- Axis1: f (F7, F8): the risk of opportunism of the liquidators (OPP.LIQUI);

- Axis2: $f(F 2, F 3, F 4)$ : the malfunction of the judicial system and ineffectiveness of the recovery procedures (INEF.REC);

- Axis3: $\mathrm{f}$ (F5): the order of priority of the creditors (PRIORITY);

- Axis4: $\mathrm{f}(\mathrm{F} 1, \mathrm{F9})$ : the difficulty of repayment in case of bankruptcy (DIF.REP).

The index of KMO which measures the degree of accuracy of the sampling exceeds 0.5 and Bartlett's test shows that the representation is very significant. This shows that at this level the representation is good and most of the variables are well presented.

4 axes are representing the importance of the dysfunction of recovery procedures:

- Axis 1, entitled "the risk of opportunism of the liquidators (OPP.LIQUI)" explains this problem at 23.76\%;

- Axis 2, entitled "malfunction of the judicial system and ineffectiveness of the recovery procedures (INE.RECV)" explains the problem to the order of $16.9 \%$;

- Axis 3, entitled "order of priority of the creditors (PRIORITY)" explains the malfunction recovery procedures in Tunisia at $14,6 \%$;

- Axis 4, entitled "difficulty of repayment in case of bankruptcy (DIF.REP)" represents $13.8 \%$ of the malfunctioning of the judicial system.

In total, these four components explain $69.07 \%$ of the total variance explained. We note that the first one "OPP.LIQUI" is the best presented

We are going to integrate the built components as the explanatory variables of the credit rationing.

\section{The Estimation of the Model by the Logit Method: A Non-Linear Probability Model}

Through this econometric analysis, we will highlight the determinants of the credit rationing decisions in Tunisia. The dependent variable $\mathrm{Y}$ comes in the form of a qualitative answer of Yes or No type. It takes two values: 0 for No and 1 for Yes:

$Y_{i}=1$ If the bank does not grant credit;

$Y_{i}=0$ If the bank grants credit. 
The variables that may influence the decision are noted Xi. They are numbering 11: EN.INF, R.DOC, ANTISEL, GARANTI, OPP.LIQ, INE.RECV, PRIORITY, R.PRUD, I.DD, DIFF.REM, OPP.B.

Table 2. Definition of the explanatory variables

\begin{tabular}{ll}
\hline Variables $\mathbf{X}_{\mathbf{i}}$ & Definition \\
\hline N.EINF & Asymmetric nature of the information environment \\
R.DOC & Reliability of accounting documents \\
ANTISEL & Anti-selection problem \\
GARANTI, & Lack of Guarantee \\
OPP.LIQ & Opportunism of the liquidators \\
INE.RECV & Ineffectiveness of the recovery procedures \\
PRIORITY & Order of priority of Creditors \\
R.PRUD & Respect of prudential ratios \\
I.DD & Importance of doubting debts \\
DIFF.REP & Difficulty of repayment \\
OPP.B* & Opportunism of borrowers \\
\hline This variable reflects the existence of the problem of the moral hazard
\end{tabular}

We specify the relationship between the explanatory variables Xi and the dependent variable Yi through a logit model as follows:

$$
Y_{i}=\phi\left(\alpha+\beta X_{i}\right)+\varepsilon_{i}
$$

$\phi$ is a distribution function of the logistic law, its realization falls in 0 and $1: \quad \phi\left(\alpha+\beta X_{i}\right)=\frac{\exp \frac{\alpha+\beta X_{i}}{1+\exp } \alpha+\beta X_{i}}{{ }_{i}}$

The most important step consists in determining the signs of the $\beta_{j}$ coefficients and their relative values. Since we know the values of the explanatory variables, we can determine the values of the coefficients. If the coefficient is positive, this shows that the increase of $X_{i}$ implies a greater probability that $Y_{i}$ is equal to 1 .

\subsection{Results and Discussion}

When we introduced all the components built by the principal component analysis method, the properties of the model were not good as shown in the model specification tests, the model obtained has a relatively weak explanatory power. It must be said that the indicators used in linear models serving to the assessment of the quality of the model as the square of residues and the Fisher statistic do not apply in the case of the quality choice models. For that reason, the Fisher statistic is substituted by the log-likelihood.

The R-square Nagelkerke indicates that only $26 \%$ of the variation in credit rationing probability could be explained by the set of explanatory variables. Most of the variables observed show coefficients with expected signs accordingly to the findings of the literature. Only three variables are significant: the reliability of accounting documents, the risk of anti-selection and the ineffectiveness of the recovery procedures. This reflects the fact that from the 120 credit managers' sample, the credit rationing decision is taken on the basis of these three variables.

Table 3. The Logit model outcomes

\begin{tabular}{lllllll}
\hline & B & E.S. & Wald & Dol & Signif. & Exp(B) \\
\hline ENINF &,- 127 &, 205 &, 382 & 1 &, 536 &, 881 \\
R.DOC &,- 352 &, 211 & 2,773 & 1 &, $096^{*}$ &, 704 \\
ANTISEL &, 375 &, 212 & 3,124 & 1 &, $077^{*}$ & 1,455 \\
GARANTI &, 293 &, 227 & 1,665 & 1 &, 197 & 1,340 \\
OPP.LIQ &, 009 &, 212 &, 002 & 1 &, 966 & 1,009 \\
INE.RECV &, 404 &, 215 & 3,553 & 1 &, $059 *$ & 1,498 \\
PRIORITY &,- 067 &, 201 &, 111 & 1 &, 739 &, 935 \\
DIFF.REP &,- 220 &, 208 & 1,125 & 1 &, 289 & 1,247 \\
R.PRUD &,- 049 &, 218 &, 050 & 1 &, 824 &, 953 \\
I.DD &, 187 &, 210 &, 794 & 1 &, 373 &, 829 \\
OPP.B &, 254 &, 460 &, 305 & 1 &, 581 &, 776 \\
Constant &, 952 & 1,075 &, 785 & 1 &, 376 & 2,592 \\
\hline
\end{tabular}

* significant coefficient at the $10 \%$ level. 
To improve the overall significance of the model, we have only selected the variables which better explain the credit rationing: R.DOC, ANTISEL, INERECV.

By retaining only significant variables, the adequacy and the overall significance of the model have largely improved (see Table 4 and Table 5).

Table 4. Tests of the model specification

\begin{tabular}{lllll}
\hline & & chi-square & Degree of liberty & Sig \\
\hline Step 1 & step & 8,922 & 3 &, 030 \\
& Bloc & 8,922 & 3 &, 030 \\
& Model & 8,922 & 3 &, 030 \\
\hline
\end{tabular}

Table 5. The model summary

\begin{tabular}{llll}
\hline step & $-2 \log$-likelihood & R-square of Cox and Snell & R-square Nagelkerke \\
\hline 1 & $149,087(a)$ &, 362 &, 456 \\
\hline
\end{tabular}

The Analysis of Tables 4 and 5 shows that the model is generally adequate. The variables are those that seem to be the most important in the credit rationing explanation. The R-square of Cox and Snell is 0.362. It indicates that $36 \%$ of the variation in the credit rationing probability could be explained by the explanatory variables used. However, the R-square of Nagelkerke representing an adjusted version of R-square of Cox \& Snell is around 0,45 . We can say that the explanatory variables explain $45 \%$ of the variation in the credit rationing probability. The explanatory power of the model has become relatively important.

Table 6 shows that the predictive power of the model is also satisfactory. The model predicts $65.8 \%$ of cases.

Table 6. The model predictive power

\begin{tabular}{|c|c|c|c|c|}
\hline \multirow{3}{*}{ Observed } & & \multicolumn{3}{|c|}{ expected } \\
\hline & & \multicolumn{2}{|c|}{$\begin{array}{l}\text { b2/ If Lack of information about } \\
\text { the company, you decide: }\end{array}$} & \multirow[t]{2}{*}{$\begin{array}{c}\text { Correct } \\
\text { pourcentage }\end{array}$} \\
\hline & & Grant credit & Don't grant credit & \\
\hline step 1 !/ If Lack of information about the company, you decide: & grant credit & 22 & 28 & 44,0 \\
\hline & Don't grant credit & 13 & 57 & 81,4 \\
\hline global percentage & & & & 65,8 \\
\hline
\end{tabular}

\subsection{The Determinants of the Credit Rationing}

The estimation of the model highlights the following equation:

$$
p(Y=1)=0,357-0,363 R \cdot D O C+0,376 \text { ANTISEL }+0,345 I N E \cdot R E C V+\varepsilon
$$

Table 7. Variables in the equation

\begin{tabular}{lllllll}
\hline & B & E.S. & Wald & Dol & Signif. & $\operatorname{Exp(B)}$ \\
\hline R.DOC &,- 363 &, 197 & 3,394 & 1 &, $065^{*}$ &, 696 \\
ANTISEL &, 376 &, 196 & 3,670 & 1 &, $055^{*}$ & 1,457 \\
INE.RECV &, 345 &, 197 & 3,048 & 1 &, $081^{*}$ & 1,411 \\
A Constant &, 357 &, 193 & 3,434 & 1 &, $064 *$ & 1,429 \\
\hline
\end{tabular}

* coefficient significant at the $10 \%$ level.

The variables with positive coefficients as ANTISEL et INERECV positively impact the rationing credit decision. Those with negative coefficients as "R.DOC" negatively affect the rationing credit decision. These findings show that the credit managers care especially about the ex-ante information asymmetry problem that causes the phenomenon of anti-selections as well as the lack of reliability of the documents submitted by the companies. We also note that the ineffectiveness of the recovery procedures induces the credit rationing. Most of the interviewees think that the laws of bankruptcies are set by the authorities for the only benefit of the borrowers to allow them to 
maintain their activities as long as possible.

\section{Conclusion}

In this paper, we have identified the determinants of credit rationing based on theoretical models that have been developed in this direction. From this theoretical research, we have established a semi- directive inquiry sent to 120 credit managers. The results show that Tunisian credit managers are risk averse despite the phenomenon of competition which is being widening between various banks. The findings assert that the credit managers use several ways to reduce the information asymmetry by the opening of individuals accounts, the requirement of reliable accounting documents sometimes certified by auditors as well as a mortgage collateral requirements sometimes the borrowers are not able to provide and finally by the use of the central risk system in order to get the history of the borrower. The Tunisian bankers don't much matter about the moral hazard problem because of the importance of the monitoring operations, the building of a long-term relationship with his customer and the importance of the restrictive covenants forcing the borrower to honor his commitments. The Tunisian banker explains his requirement toward the Tunisian companies mainly by the unreliability of the accounting documents submitted the importance of the adverse selection and by the slow recovery procedures in case of deficiency of the debtor. In such a case, the banker would rather not engage in a risky affair so that he would not undergo considerable losses if the company is in financial distress.

\section{References}

Binks, M., Ennew, C., \& Reed, G. (1991). Small businesses and their Banks, An International Perspective. National West minster Bank.

Diamond, D. (1991). Debt Maturity Structure and Liquidity Risk. Quarterly Journal of Economics, 106, 1027-1054.

Hodgman, D. R. (1960). Credit Risk and Credit Rationing. Quarterly Journal of Economics, (2), 258-278.

Jaffee, \& Modigliani. (1969). A theory and test of credit rationing. American Economic Review, 59. Retrieved from http://faculty.haas.berkeley.edu/jaffee/papers/AERDec 1969.pdf

Jaffee, \& Russel. (1976). Imperfect information uncertainly and credit rationing. Quarterly Journal of Economics, 90.

Joseph, A. (2000). Le Rationnement de Credit dans les Pays en Développement, la cas du Cameroun et de Madagascar. Bibliothèque $\mathrm{du}$ Développement, l'Harmattan. Retrieved from http://www.alternatives-economiques.fr/le-rationnement-du-credit-dans-les-pays-en-developpement-anne-jo seph_fr_art_138_14287.html

Keeton, W. R. (1979). Equilibrium Credit Rationing. New York, Garland Publishing Inc.

Peterson, M., \& Rajan, R. (2002). Does Distance Still Matter? The Information Revolution in Small Business Lending. Journal of Finance, 57, 2533-2570.

Stiglitz, \& Weiss. (1981). Credit rationing in market with imperfect information. American Economic Review, 71, 393-410. Retrieved from http://ssrn.com/abstract=1505257

\section{Appendix}

Appendix 1. Presentation of the studied sample (At bank branches the responsible met is the head of the agency)

\begin{tabular}{llllll}
\hline & Location & Capital & Year of creation & Number of agencies & the function of the interviewee \\
\hline STB & TUNIS & 124 & 1958 & 116 & Credit manager SME \\
BH & TUNIS & 90 & 1989 & 65 & - \\
BNA & - & 130 & 1958 & 145 & - \\
BMPME & - & 50 & 2005 & 5 & - \\
BTS & - & 40 & 1997 & 25 & - \\
BIAT & - & 170 & 1976 & 108 & - \\
ATB & - & 60 & 1981 & 100 & - \\
UIB & - & 106 & 1963 & 100 & - \\
TIB & - & 40 & 1992 & 5 & - \\
UBCI & - & 50 & 1962 & 97 & - \\
ATTIJARI & - & 100 & 1968 & 29 & - \\
\hline
\end{tabular}




\begin{tabular}{llllll}
\hline BANK & & & & \\
BT & - & 75 & 1884 & 83 & - \\
AMEN BANK & - & 85 & 1995 & 95 & - \\
CITI BANK & - & 25 & & 10 & - \\
STUSID BANK & - & 100 & 1963 & 5 & - \\
ABC BANK & - & 40 & 1993 & 3 & - \\
BTE & - & 90 & 1981 & 5 & - \\
TQB & - & 30 & 1982 & 5 & - \\
BTK & - & 40 & 1981 & 5 & - \\
BFT & - & 5 & 1979 & 5 & \\
\hline
\end{tabular}

Appendix 2. Survey on the behavior of SME clients account managers and credit distribution

\section{A. The credit rationing}

A1. In the case of a lack of information on the company, you decide to:

- raise the interest rate

- require guarantees, and if so which kind:

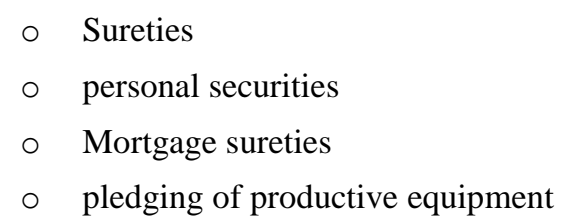

- not to grant a credit

- introduce restrictive clauses,

$\circ \quad$ if so: which kind?

A2. When the company seems to be risky, you decide to :

- rise the interest rate

- not to grant a credit

- introduce restrictive clauses, if so which kind?

B. Credit rationing and capacity of credit supply

B1. Is the credit supply capacity limited by the respect of some prudential ratios that requires you to hold -as currency availability- a part of the savings collected?

- Yes

- No

- why?

B2. Are the provisions to be constituted high?

-Yes

-No

B3. Do you encounter refinancing difficulties at the BCT?

- Often

- sometimes

- Never

B4. Are doubtful debts important?

- Often

- sometimes

- Never

B5. Is there a trust issue between banks? 
- Often

- sometimes

- Never

C. the credit rationing and the anti-selection risk

C1. Has the economic environment changed after the implementation of the structural adjustment plan?

- Yes

- No

C2.If so, has the change in the economic environment increased the difficulty of the risk assessments of projects?

- Yes

- No

C3. Do you easily get information on potential borrowers?

- Often

- sometimes

- Never

C4. Is there a lack of reliability on the accounting information provided by the companies?

- Often

- sometimes

- Never

C5. Does the auditing of these documents by statutory auditors represent a reliability criterion for you ?

- Often

- sometimes

- Never

-Why?

C6. Do you think there is a bribery issue at this stage?

- Often

- sometimes

- Never

C7. Are the softwares available at banks to restate corporate balance sheets and detect inconsistencies always able to assess the business risk?

- Often

- sometimes

- Never

-why?

C8. A borrower who accepts a high interest rate is:

- A good client

- A badly managed company

-A risky company

C9. A borrower who accepts to give a lot of guarantees is:

- A good client

- A badly managed company

- A risky company 
D. The credit rationing and the moral hazard

D1. When a credit is granted, do companies try to change the project?

- Often

- sometimes

- Never

D2. Is there a followed of the various stages of the project funding?

- Often

- sometimes

- Never

D3. Do companies hide their financial information (their turnover, their profitability for example) to get a loan?

- Often

- sometimes

- Never

- Why?

D4. Generally, do you encounter difficulties to collect your receivables?

- Often

- sometimes

- Never

E. Guarantees

E1. Do you require a lot of guarantees or are you requiring in terms of guarantees?

- Often

- sometimes

- Never

E2. Even when the company accepts to give the required guarantees, do you remain as much prudent?

- Often

- Sometimes

- Never

F. Dysfunction of judicial proceedings

F1. In the case of the company bankruptcy, do you have difficulties to recover your debts?

- Often

- Sometimes

- Never

F2. If so, do you think that this is partly due to the ineffectiveness of the recovery procedures?

- Often

- Sometimes

- Never

F3. Is prudence before committing related to the failure of the judicial system and to the anti-bank behavior of courts?

- Yes

- No

F4. Do you find yourself in a conflict situation with debtors?

- Often 
- Sometimes

- Never

F5. Among creditors, is the bank a priority?

- Often

- Sometimes

- Never

F6. Is the liquidator still a court expert in accounting and registered on the lists in the courts?

- Often

- Sometimes

- Never

F7. Do you think that the liquidators seek to maximize their personal income and not the company's value?

- Often

- Sometimes

- Never

F8. Do you think that some liquidators withhold information to reduce the creditor control power?

- Often

- Sometimes

- Never

F9. Do you think bankruptcy laws are pro-borrowers and non-pro-creditors?

- Yes

- No

G. The company's signaling on the credit market

G1. Is the financial structure of the firm important for you?

- Yes

- No

- Why?

G2. Does the property structure of the firm impact your decision depending on whether there are : micro enterprises, small and medium enterprises or large enterprises publicly traded ?

- Yes

- No

- Why?

G3. Is the capital participation of other companies for the granting of credit, a factor:

- Favorable

- Unfavorable

- Indifferent

G4. Is your relationship with the manager harder when the company is a member of a corporate group?

- Often

- Sometimes

- Never

G5. Does the existence of a relationship between your customer and a large company constitute a signal of the quality of the company?

- Often 
- Sometimes

- Never

G6. If the company has already undergone audits as part of these relationships, do you require the reports?

- Often

- Sometimes

- Never

G7. Do you favor some sectors than others?

-Yes

-No

G8. Which sector de you prefer?

-Manufacturing industries

-Non- manufacturing industries

-Service

-Agriculture

H. The terms of financing contracts

H1. If a client gives you very "safe" guarantees, do you decrease the interst rate?

- Often

- Sometimes

- Never

H2. Does the risk premium decrease with:

- The size

$\begin{array}{cc}\text { Yes } & \text { No } \\ \text { Yes } & \text { No } \\ \text { Yes } & \text { No } \\ \text { Yes } & \text { No } \\ \text { Yes } & \text { No }\end{array}$

- The time

No

- The stock market listing of the firm No

- The activity branch No

- The conjuncture

I. The monitoring operations performed by the "chargé d'affaires"

I1. How do you control the evolution of the activity of the company once the loan is granted?

-The turnover evolution

- The account Movement

- The followed of the deblocking

- Visits

I2. How many times per year do you contact the company?

-2 to 4 times

- 4 to 6 times

- 6 to 10 times

- More than 10 times

I3. How many times per year do you meet the financial manager of the company?

-2 to 4 times

-4 to 6 times

- 6 to 10 times

- More than 10 times 


\section{I4. Do you require intermediate accounting states?}

-Yes

-No

-Which kind?

\section{J. The relationship bank-SME}

J1. Does a contractor who solicits a bank for the first time have little chance of obtaining funding?

- Often

- Sometimes

- Never

J2. What is the degree of trust you granted to a new customer?

- High

- Medium

- Weak

J3. Do you inquire the same information to over than a year -clients and to over than 5 years-ones?

-Yes

- No

J4. Do you inquire the same information to less than a year -clients and over than 5years-ones?

-Yes

- No

J5. Do you inquire the same information to SME and to large ones?

- Often

- Sometimes

- Never

\section{Appendix 3. PCA 1}

Table 3.1. KMO index and Bartlett test

\begin{tabular}{lll}
\hline Sampling precision measurement of Kaiser-Meyer-Olkin. &, 507 \\
\hline Bartlett 's Test of sphericity & chi squared approximation & 13,877 \\
& degree of liberty & 6 \\
& Bartlett signification &, $031^{* *}$ \\
\hline
\end{tabular}

** Significant at $5 \%$.

Table 3.2. Quality of the representation

\begin{tabular}{|c|c|c|}
\hline & Initial & Extraction \\
\hline B1 / Is the credit supply capacity limited by the respect of prudential ratios? & 1,000 & ,646 \\
\hline B2 / Are the provisions to be constituted high? & 1,000 & ,625 \\
\hline B3 / Do you encounter refinancing difficulties at the BCT? & 1,000 & ,367 \\
\hline B4 / Are doubting debts important? & 1,000 &, 731 \\
\hline
\end{tabular}

Extraction Method: Principal component analysis.

Table 3.3. Total variance explained

\begin{tabular}{|c|c|c|c|c|c|c|c|c|c|}
\hline \multirow[t]{2}{*}{ Element } & \multicolumn{3}{|c|}{ Initial values } & \multicolumn{3}{|c|}{$\begin{array}{c}\text { Sums of squares of selected factors } \\
\text { Extraction }\end{array}$} & \multicolumn{3}{|c|}{$\begin{array}{c}\text { Sums of squares of retained factors for } \\
\text { the rotation }\end{array}$} \\
\hline & Total & $\%$ of the variance & $\%$ cumulated & Total & $\%$ of the variance & $\%$ cumulated & Total & $\%$ of the variance & $\%$ cumulated \\
\hline 1 & 1,352 & 33,805 & 33,805 & 1,352 & 33,805 & 33,805 & 1,320 & 33,004 & 33,004 \\
\hline 2 & 1,017 & 25,415 & 59,220 & 1,017 & 25,415 & 59,220 & 1,049 & 26,216 & 59,220 \\
\hline 3 & ,954 & 23,855 & 83,075 & & & & & & \\
\hline 4 & 677 & 16,925 & 100,000 & & & & & & \\
\hline
\end{tabular}

Extraction Method: Principal component analysis. 
Table 3.4. Matrix components after rotation (a)

\begin{tabular}{lcc}
\hline & \multicolumn{2}{c}{ Component } \\
\cline { 2 - 3 } B1 / Is the credit supply capacity $\quad$ limited by the respect of prudential ratios? & 1 & 2 \\
B2 / Are the provisions to be constituted high? &, 776 &,- 207 \\
B3 / Do you encounter refinancing difficulties at the BCT? &, 784 &, 100 \\
B4 / Are doubting debts important? &, 278 &,- 538 \\
\hline
\end{tabular}

Extraction Method: Principal component analysis.

Rotation Method: Varimax with kaiser normalisation.

(a) Rotation converged to 3 iterations.

\section{Appendix 4. PCA2}

Table 4.1. KMO index and Bartlett test

\begin{tabular}{lll}
\hline Sampling precision measurement of Kaiser-Meyer-Olkin. &, 464 \\
\hline Bartlett 's Test of sphericity & chi squared approximation & 28,063 \\
& degree of liberty & 21 \\
& Bartlett signification &, 138 \\
\hline
\end{tabular}

Table 4.2. Representation quality

\begin{tabular}{lcc}
\hline & Initial & Extraction \\
\hline C3 / Do you easily get information on potential borrowers ? & 1,000 &, 404 \\
C4 / Is there a lack of reliability on the accounting information provided by the companies ? & 1,000 &, 573 \\
C5 / Does the auditing of these documents by statutory auditors represent a reliability criterion for you ? & 1,000 &, 679 \\
C6 / Do you think there is a bribery issue at this stage? & 1,000 &, 517 \\
C7 / Are softwares available to banks to restate corporate balance sheets and detect inconsistencies always & 1,000 &, 412 \\
able to assess the business risk? & 1,000 &, 532 \\
C8 / A borrower who accepts a high interest rate is : & 1,000 &, 637 \\
C9 / A borrower who accepts to give a lot of guarantees is: & \\
\hline
\end{tabular}

Extraction method: principal component analysis.

Table 4.3. Total variance explained

\begin{tabular}{|c|c|c|c|c|c|c|c|c|c|}
\hline \multirow[t]{2}{*}{ Component } & \multicolumn{3}{|c|}{ Initial values } & \multicolumn{3}{|c|}{ Sums of squares of selected factors } & \multicolumn{3}{|c|}{$\begin{array}{l}\text { Sums of squares of retained factors } \\
\text { for the rotation }\end{array}$} \\
\hline & Total & $\%$ of variance & $\%$ cumulated & Total & $\%$ of the variance & $\%$ cumulated & Total & $\%$ of the variance & $\%$ cumulated \\
\hline 1 & 1,392 & 19,887 & 19,887 & 1,392 & 19,887 & 19,887 & 1,357 & 19,385 & 19,385 \\
\hline 2 & 1,286 & 18,366 & 38,253 & 1,286 & 18,366 & 38,253 & 1,243 & 17,762 & 37,147 \\
\hline 3 & 1,078 & 15,395 & 53,648 & 1,078 & 15,395 & 53,648 & 1,155 & 16,501 & 53,648 \\
\hline 4 & ,968 & 13,832 & 67,480 & & & & & & \\
\hline 5 &, 862 & 12,316 & 79,796 & & & & & & \\
\hline 6 & 819 & 11,702 & 91,498 & & & & & & \\
\hline 7 &, 595 & 8,502 & 100,000 & & & & & & \\
\hline
\end{tabular}

Extraction method: principal component analysis.

Table 4.4. Component matrix after rotation (a)

\begin{tabular}{lccc}
\hline & \multicolumn{2}{c}{ Component } \\
\cline { 2 - 3 } & 1 & 2 & 3 \\
\hline C3 / Do you easily get information on potential borrowers? &, 616 &,- 142 &, 069 \\
C4 / Is there a lack of reliability on the accounting information provided by the companies? &, 196 &, 725 &,- 090 \\
C5 / Does the auditing of these documents by statutory auditors represent a reliability criterion for you? &, 803 &, 166 &,- 082 \\
C6 / Do you think there is a bribery issue at this stage? &,- 378 &, 612 &,- 026 \\
C7 / Are softwares available to banks to restate corporate balance sheets and detect inconsistencies always able &,- 023 &, 542 &, 343 \\
to assess the business risk? &,- 023 \\
\hline
\end{tabular}




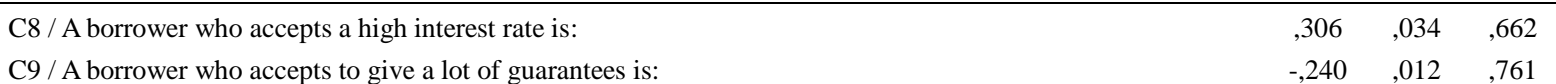

C9/Aborrower who accepts to give a lot of guarantees is:

Extraction Method: Principal component analysis.

Rotation Method: Varimax with kaiser normalisation.

(a) Rotation converged to 5 iterations.

\section{Appendix 5. PCA 3}

Table 5.1. KMO index and Bartlett test(a)

\begin{tabular}{lll}
\hline \multicolumn{2}{l}{ Sampling precision measurement of Kaiser-Meyer-Olkin. } &, 500 \\
\hline Bartlett 's Test of sphericity & chi squared approximation & 1,092 \\
& degree of liberty & 1 \\
& Bartlett signification &, 296 \\
\hline
\end{tabular}

(a) Based on correlations.

Table 5.2. Representation quality

\begin{tabular}{lllll}
\hline & not normed & \multicolumn{3}{c}{ resized } \\
\cline { 2 - 5 } & Initial & Extraction & Initial & Extraction \\
\hline D1 / When a credit is granted, do companies try to change the project? &, 245 &, 180 & 1,000 &, 732 \\
D4 / Generally, do you encounter difficulties to collect your receivables? &, 227 &, 081 & 1,000 &, 357 \\
\hline
\end{tabular}

Extraction Method: Principal component analysis.

Table 5.3. Total variance explained

\begin{tabular}{lccccccc}
\hline & Component & \multicolumn{5}{c}{ Initial values (a) } & \multicolumn{2}{c}{ Sums of squares of selected factors Extraction } \\
\cline { 3 - 7 } & & Total & \% of the variance & \% cumulated & Total & \% of the variance & $\%$ cumulated \\
\hline \multirow{2}{*}{ not normalized } & 1 &, 261 & 55,191 & 55,191 &, 261 & 55,191 & 55,191 \\
& 2 &, 212 & 44,809 & 100,000 & & & 54,454 \\
\multirow{2}{*}{ resized } & 1 &, 261 & 55,191 & 55,191 & 1,089 & 54,454 & \\
& 2 &, 212 & 44,809 & 100,000 & & & \\
\hline
\end{tabular}

Extraction Method: Principal component analysis.

(a) At the analysis of a covariance matrix, the initial values of the direct and centered solutions are the same.

Table 5.4. Component matrix

\begin{tabular}{lll}
\hline & Not normed Component & Resized Component \\
\cline { 2 - 3 } & 1 & 1 \\
\hline D1 / When a credit is granted, do companies try to change the project? &, 424 &, 856 \\
D4 / Generally, do you encounter difficulties to collect your receivables? &, 285 &, 598 \\
\hline
\end{tabular}
Extraction Method: Principal component analysis.

(a) 1 component extracted.

\section{Appendix 6. PCA 4}

Table 6.1. KMO index and Bartlett test

\begin{tabular}{lll}
\hline \multicolumn{2}{l}{ Sampling precision measurement of Kaiser-Meyer-Olkin. } &, 500 \\
\hline Bartlett 's Test of sphericity & chi squared approximation & 2,890 \\
& degree of liberty & 1 \\
& Bartlett signification &, 89 \\
\hline
\end{tabular}

Table 6.2. Representation quality

\begin{tabular}{llc}
\hline & Initial & Extraction \\
\hline E1 / Do you require a lot of guarantees or are you requiring in terms of guarantee? & 1,000 &, 578 \\
E2 / Even when the company accepts to give the required guarantees, do you remain as much prudent? & 1,000 &, 578 \\
\hline
\end{tabular}

Extraction Method: Principal component analysis. 
Table 6.3. Total Variance explained

\begin{tabular}{lcccccc}
\hline Component & \multicolumn{3}{c}{ Initial values } & \multicolumn{2}{c}{ Sums of squares of selected factors Extraction } \\
\cline { 2 - 6 } & Total & \% of the variance & $\%$ cumulated & Total & $\%$ of the variance & $\%$ cumulated \\
\hline 1 & 1,156 & 57,794 & 57,794 & 1,156 & 57,794 & 57,794 \\
2 &, 844 & 42,206 & 100,000 & & & \\
\hline
\end{tabular}

Extraction Method: Principal component analysis.

Table 6.4. Component matrix (a)

\begin{tabular}{lll}
\hline Component & 1 \\
\hline E1 / Do you require a lot of guarantees or are you requiring in terms of guarantee? &, 760 \\
E2 / Even when the company accepts to give the required guarantees, do you remain as much prudent? &, 760 \\
\hline
\end{tabular}
Extraction Method: Principal component analysis.

(a). 1 component extracted.

\section{Appendix 7. PCA 5}

Table 7.1. KMO index and Bartlett test

\begin{tabular}{lll}
\hline \multicolumn{2}{l}{ Sampling precision measurement of Kaiser-Meyer-Olkin. } &, 522 \\
\hline Bartlett 's Test of sphericity & chi squared approximation & 96,998 \\
& degree of liberty & 28 \\
& Bartlett signification &, 000 \\
\hline
\end{tabular}

Table 7.2. Representation quality

\begin{tabular}{lcc}
\hline & Initial & Extraction \\
\hline F1 / In the case of the company bankruptcy, do you have difficulties to recover your debts? & 1,000 &, 758 \\
F2 / If so, do you think that this is partly due to the ineffectiveness of the recovery procedures? & 1,000 &, 588 \\
F3 / Is prudence before committing related to the failure of the judicial system and to the anti-bank behavior of & 1,000 &, 704 \\
courts? & 1,000 &, 477 \\
F4 / Do you find yourself in a conflict situation with debtors? & 1,000 &, 852 \\
F5 / Among creditors, is the bank a priority? & 1,000 &, 731 \\
F7 / Do you think that the liquidators seek to maximize their personal income and not the company's value? & 1,000 &, 686 \\
F8 / Do you think that some liquidators withhold information to reduce the creditor control power? & 1,000 &, 729 \\
F9 / Do you think bankruptcy laws are pro-borrowers and non- pro-creditors? &
\end{tabular}

Extraction Method: Principal component analysis.

Table 7.3. Total Variance explained

\begin{tabular}{|c|c|c|c|c|c|c|c|c|c|}
\hline \multirow[t]{2}{*}{ Component } & \multicolumn{3}{|c|}{ Initial values } & \multicolumn{3}{|c|}{$\begin{array}{c}\text { Sums of squares of selected factors } \\
\text { Extraction }\end{array}$} & \multicolumn{3}{|c|}{$\begin{array}{c}\text { Sums of squares of selected factors for } \\
\text { the rotation }\end{array}$} \\
\hline & Total & $\begin{array}{l}\% \text { of the } \\
\text { variance }\end{array}$ & $\%$ cumulated & Total & $\begin{array}{l}\% \text { of the } \\
\text { variance }\end{array}$ & $\%$ cumulated & Total & $\begin{array}{l}\% \text { of the } \\
\text { variance }\end{array}$ & $\begin{array}{c}\% \\
\text { cumulated }\end{array}$ \\
\hline 1 & 1,901 & 23,769 & 23,769 & 1,901 & 23,769 & 23,769 & 1,625 & 20,316 & 20,316 \\
\hline 2 & 1,352 & 16,906 & 40,675 & 1,352 & 16,906 & 40,675 & 1,559 & 19,486 & 39,802 \\
\hline 3 & 1,168 & 14,601 & 55,276 & 1,168 & 14,601 & 55,276 & 1,190 & 14,874 & 54,676 \\
\hline 4 & 1,104 & 13,800 & 69,076 & 1,104 & 13,800 & 69,076 & 1,152 & 14,400 & 69,076 \\
\hline 5 &, 823 & 10,284 & 79,360 & & & & & & \\
\hline 6 &, 675 & 8,442 & 87,802 & & & & & & \\
\hline 7 &, 549 & 6,865 & 94,666 & & & & & & \\
\hline 8 &, 427 & 5,334 & 100,000 & & & & & & \\
\hline
\end{tabular}

Extraction Method: Principal component analysis. 
Table 7.4. Component matrix after rotation (a)

\begin{tabular}{|c|c|c|c|c|}
\hline & \multicolumn{4}{|c|}{ Component } \\
\hline & 1 & 2 & 3 & 4 \\
\hline F1 / In the case of the company bankruptcy, do you have difficulties to recover your debts? & ,473 &, 363 &,- 310 &,- 553 \\
\hline F2 / If so, do you think that this is partly due to the ineffectiveness of the recovery procedures? & ,080 &, 746 &, 013 &, 156 \\
\hline $\begin{array}{l}\text { F3 / Is prudence before committing related to the failure of the judicial system and to the anti-bank } \\
\text { behavior of courts? }\end{array}$ & ,256 & ,640 & ,462 &, 129 \\
\hline F4 / Do you find yourself in a conflict situation with debtors? &,- 214 & ,647 &,- 059 &,- 097 \\
\hline F5 / Among creditors, is the bank a priority? & ,041 & ,028 & ,914 &,- 116 \\
\hline $\begin{array}{l}\text { F7 / Do you think that the liquidators seek to maximize their personal income and not the company's } \\
\text { value? }\end{array}$ & 843 &,- 048 & ,070 &,- 116 \\
\hline F8 / Do you think that some liquidators withhold information to reduce the creditor control power? &, 741 &,- 001 & ,052 &, 367 \\
\hline F9 / Do you think bankruptcy laws are pro-borrowers and non- pro-creditors? &, 151 &, 197 &,- 182 & ,797 \\
\hline
\end{tabular}

Extraction Method: Principal component analysis.

Rotation Method: Varimax with kaiser normalisation.

(a) Rotation converged to 16 iterations.

\section{Appendix 8. The Logit model outcomes}

Table 8.1. Codification of the dependent variables

\begin{tabular}{ll}
\hline Original value & internal value \\
\hline Grant a credit & 0 \\
Not to grant a credit & 1 \\
\hline
\end{tabular}

Table 8.2. Classification table (a)

\begin{tabular}{|c|c|c|c|c|c|}
\hline \multirow{3}{*}{\multicolumn{2}{|c|}{ Observed }} & & \multicolumn{3}{|c|}{ expected } \\
\hline & & & \multicolumn{2}{|c|}{$\begin{array}{l}\text { b2/ If Lack of information about the } \\
\text { company, you decide: }\end{array}$} & \multirow[t]{2}{*}{ correct percentage } \\
\hline & & & Grant a credit & Not to grant a credit & \\
\hline \multirow[t]{3}{*}{ stage1 } & $\begin{array}{l}\text { b2/ If Lack of information about } \\
\text { the company, you decide }\end{array}$ & Grant a credit & 26 & 24 & 52,0 \\
\hline & & Not to grant a credit & 11 & 59 & 84,3 \\
\hline & global percentage & & & & 70,8 \\
\hline
\end{tabular}

(a) The caesura value is, 500 .

Table 8.3. The specification tests of the model

\begin{tabular}{lllll}
\hline & & chi-square & dol & Signif. \\
\hline stage1 & stage & 13,920 & 11 &, 137 \\
& Bloc & 13,920 & 11 &, 137 \\
& Model & 13,920 & 11 &, 137 \\
\hline
\end{tabular}

Table 8.4. The model summary

\begin{tabular}{llccc}
\hline stage & -2 log-likelihood & R-square of & Cox \& Snell & R-square of Nagelkerke \\
\hline 1 & $154,085(\mathrm{a})$ &, 110 & &, 267 \\
\hline
\end{tabular}

(a) The estimation was stopped at the $4^{\text {th }}$ iteration because parameter estimations changed by less than .001 .

\section{Copyrights}

Copyright for this article is retained by the author(s), with first publication rights granted to the journal.

This is an open-access article distributed under the terms and conditions of the Creative Commons Attribution license (http://creativecommons.org/licenses/by/3.0/). 